\title{
Preparing for High-Mix of Renewables in India's Power Generation
}

\author{
Ashok Jhunjhunwala ${ }^{1}$ Prabhjot Kaur ${ }^{1} \mathbb{C}$
}

Received: 28 April 2017 / Accepted: 15 June 2017 / Published online: 13 July 2017

(C) Springer Nature Singapore Pte Ltd. 2017

\begin{abstract}
Coal and Renewables (especially solar and wind) are likely to dominate India's energy mix for quite some time. India is blessed with solar radiation in most parts of the country, and costs are falling rapidly. It is conceivable that power-generation using renewables is likely to come close to $50 \%$ by 2030 . While this could be great for India, the intermittent power-generation through wind and solar would imply that power-available may fluctuate. Battery Storage could be an answer. Even though cost of Battery Storage is falling rapidly, grid-level storage to arrest powergeneration fluctuation would push the prices of electric power beyond "affordability" in India. The other answer is demand side load-management to significantly off-set the supply variation without impacting living and working style significantly. The paper briefs on design of power-system in multi-storied commercial complexes, which would make its electrical load respond to power-surplus and power-deficit scenarios on the grid. When the grid has surplus power, the building would consume power to its full extent, but when there is power-deficit, it will consume minimally. Such buildings are being built today, and if tariffs are designed to benefit commercial complexes which adhere to the above principal, their adoption would be speeded up. The key is that it would benefit the grid, while benefitting the commercial complexes. Besides presenting the concept and designs of power-systems in such buildings, the paper presents
\end{abstract}

Prabhjot Kaur

prabhjot@tenet.res.in

Ashok Jhunjhunwala

ashok@tenet.res.in

1 Electrical Engineering Department, Indian Institute of Technology Madras, Chennai, India some simulation results and some initial measurements on power-consumed in different situations in one such building. The paper also presents some initial idea on how this approach can be extended to powering entire residential and commercial sector.

Keywords APRL - Available power responsive load . Deficit grid · Energy efficiency · Normal grid . Renewables · Surplus grid

\section{Introduction}

Renewables contribute to about $18 \%$ of total power installed in India today and if we include hydro power in renewables, the percentage will go up to $31 \%$ [1]. This is not small. But in terms of total energy generated, the percentage of renewables is much less; renewables contributed only $65.94 \mathrm{BU}$ out of the total generated energy of 872.96 BU during 2016-17. In other words, renewables amounted to less than $18 \%$ energy in 2017 and hydro was $13.5 \%$ [1, 2]. But India has set up a target of $175 \mathrm{GW}$ by 2022 . If this was to be realized, the percentage of renewables may become closer to $25 \%$ in coming years.

While this will be great for the nation, the volatile, intermittent, fluctuating nature of renewable energy source could indeed present a challenge for the power-grid, unless urgent steps are taken today. The signs of the trouble is already there, where the state power distribution companies (DISCOM) or utilities either refuse to sign a Power Purchase Agreement (PPA) or refuse to draw power from renewables when available, even when they have already committed to do so. Most renewable generation (for example solar PV based generation) has high upfront capital investment and small operational cost. The costs associated with such power is therefore primarily dependent upon the depreciation and 
the interest costs (high in India) divided by the total power generated by the plant in a year. If utilities refuse to draw all the power that is available, the power gets wasted and affects the price at which the solar power-producer would be willing to sell. If there is uncertainty about whether the generated power will be drawn by the utilities or not, the producer will load the cost of uncertainty on to the power selling price (in fact manufacturers may take no risk and load the full risk), making the solar tariffs high. Incentive to go solar and renewables would therefore decrease.

So if a nation wants to go Renewables, it has to figure out a way of drawing and using ALL the renewable power generated, even though it is intermittent. It is equally important that even the non-renewable power-generation plants, with high capital costs, are not forced to back-down because of lack of demand. The problem is what would utilities do with power when there is no demand. They cannot take the losses either. The simplest solution will be for the generation companies or utilities to use some storage; but storage would be expensive. Even though the cost of storage is expected to come down $[3,4]$ in the next decade or so, it would still be high and add significantly to the total costs for the utilities. One would need an alternative strategy. This paper deals with one such alternative, that we can begin working in nearterm context and expand as renewables grow. This in-turn will help renewables to grow.

\section{Contours of the Alternative}

The simplest strategy would be to incentivize the consumers to draw more when grid has surplus power and draw less during power-deficit. If the incentives can enable a consumer to reduce his power-costs, he would invest and design his systems/buildings to respond to the grid-surplus and deficit. He will work out strategies to draw more during surplus and less during deficit. If they are able to do so, without impacting their work and lives, not only would they benefit, but so also the utilities. The utilities would be in position to draw all the available power from generating companies, which in-turn would bring down their power costs. This would lead to a big spurt for renewables and it would be a matter of time before renewables start dominating the total energy generated. In the end the nation would benefit.

For the strategy to work, the consumers would have to design their systems, buildings to respond to the available power on the grid, and have what we refer to as Available Power Responsive Load (APRL). It is important that the gains due to APRL significantly outweighs the investments required. While such APRL systems would be designed for all sectors (commercial, industrial, domestic and agricultural), one could begin with the commercial sector, as it would be most willing to take risks and make early investments. This paper would therefore look at commercial sector, and propose designs which would make commercial sense today. At a later point the approach can be extended to other sectors.

"Power Utilisation in a Multi-storied Commercial Complex" examines the power utilization for a multi-storied commercial building. "Further, Commercial Buildings Operate Mostly in Day-Time, When Sun is Available. The Buildings Could Certainly Use Roof-Top Solar Power. Space Available on the Roof-Top in such High-Rise May be Limited. Even Then it is Worth Using Whatever is Possible. Designing Buildings to Respond to Available Power" proposes some design interventions involving energy-conservation and APRL systems. In "A Case Study for a Multi-storied Building", we analyze some preliminary results of IITMRP Building, where such APRL system has been installed. "Summary and Conclusion" concludes the article.

\section{Power Utilisation in a Multi-storied Commercial Complex}

Urban areas today in most parts of the world are dominated by multi-storied complexes. India is no exception. Such buildings may be residential buildings or offices, commercial complexes, hospitals or educational institutions. While some of what we will discuss here would be applicable to even multi-storied residential buildings, the discussions here will be primarily for an office complex.

For an office buildings, the air-conditioning uses close to $50 \%$ of total energy, while office equipment may amount to $25 \%$ of building energy and lighting may consume $20 \%$ of energy used in the building. The remaining energy is used for infrastructure including water-pumps and lifts. In recent years, there has been considerable efforts to enhance energy efficiency in these buildings. The efforts have centered around enhancing efficiencies of motors used and switching to LED lighting to save energy. The air-conditioning system constitutes of high-side, which primarily consists of water chillers, pumps and cooling towers, and the low-side, which constitutes Air-handing units (AHUs), which cools air and pushes it to the individual office-rooms through dispensers. Historically, the chillers, pumps, cooling towers and AHUs all use AC induction motors, which are low-cost and simple to design, but operate at fixed revolutions per minute (rpm). Significant energy-efficiency is achieved when these motors are driven by Variable Frequency Drives (VFDs) or replaced by DC motors like BLDC or Switched Reluctance Motors. The VFDs and DC motors use DC power. The office equipment used varies with each office, but is dominated today by Personal Computers, servers, laptops (and tablets), printers, TVs, displays, projectors, and communication equipment. All the equipment use only DC power and have a built-in $\mathrm{AC}$ to DC converter when powered on an AC power-line. The lighting used today is primarily LED-based (because 
of huge energy-efficiency) and uses only DC power; each light has an AC to DC converter built in as they are connected to AC power-line. In other words, almost all building loads have evolved to be DC. The AC to DC converters needed when they are powered on conventional AC power line, have power-losses, are a point of failure and adds to the costs. On top of it, these converters, unless designed well, can impact the power-factor of an AC power-line contributing to wastage of power. Life of several of these equipment may be significantly enhanced if they could be powered on a DC power-line, see for example the studies on LEDs given in $[5,6]$. Use of DC-powered DC equipment has a potential of $20 \%$ to $50 \%$ energy savings $[7,8]$.

\section{Further, Commercial Buildings Operate Mostly in Day-Time, When Sun is Available. The Buildings Could Certainly Use Roof-Top Solar Power. Space Available on the Roof-Top in such High-Rise May be Limited. Even Then it is Worth Using Whatever is Possible. Designing Buildings to Respond to Available Power}

For a building to use more grid-power when grid has surplus and less power when grid is in deficit state, it would need storage. But the storage of electrical power on the grid was ruled out as discussed in "Contours of the Alternative", as it is expensive. The approach used here is different. Firstly, instead of centralized battery storage for the grid, the storage function is pushed to the consumer along with a redesigned tariff structure, such that the consumer benefits if the right design and investment is made to draw more power or less power from the grid based on the surplus or the deficit state of the grid. Secondly, it gives an option for the consumer to not store energy only in the electrical form, but explore other alternatives, which may be beneficial.

A building designed to be APRL would use energystorage in multiple forms. We have envisaged three forms of energy-storage here.

(i) Chilled water storage

(ii) Cold air storage

(iii) Battery storage

Each of these storages could be used to reduce powerconsumption during power-deficit situation and shift consumption during Surplus and Normal grid state. We now discuss each of these three storages in some detail.

\section{Chilled Water Storage}

A major component of power-consumption of a multistoried office complex is air-conditioning. Chilling of water constitutes almost $80 \%$ of this consumption. Chillers chill water to some low temperature (say $5{ }^{\circ} \mathrm{C}$ ) and the chilled water is pumped in insulated pipes to each floor.

It is possible to chill water and store it in an insulated chilled water storage tank and the water would remain chilled for 14 to $16 \mathrm{~h}$. This storage could be located preferably in the basement of the building, which remains cooler than the rest of the building. The chilled water could then be used at any point of time. One could have a storage tank, which stores up to $50 \%$ of the water used in a day. Such a storage would become a significant contribution to APRL system, helping minimize the energy costs for the building.

\section{Cold Air Storage}

The chilled water is taken to each wing of a floor and is used to cool air using an Air-handling Unit (AHU). The cool air is dispensed into different office-zones through air-dispensers. To enhance energy efficiency, the conventional air-dispensers are now being replaced by Variable Air Volume (VAV) air-dispenser, which measures the ambient temperature and pressure in the office zone and controls the air-opening to get the room to move towards some settemperature. The VAVs may also have proximity sensors, so that the dispenser is completely closed off, if no one is in that office-zone. The AHU senses the openings in each VAV connected to it and determines the amount of air it needs. It then uses its Variable Frequency Drive (VFD) to control the speed of the fan as well as the flow of chilled water. The amount of energy used and chilled water used is thus controlled. A well-designed controller saves significant amount of energy.

But apart from enhancing energy efficiency, the VFD / VAV combine can also be used to enable cold-air storage which can be used to increase or reduce the energy consumption in response to surplus and deficit grid situation. The storage is based on the fact that the office temperature could be varied to some extent (say $1.5^{\circ} \mathrm{C}$ ) without impacting the comfort. The air temperature could therefore be used as a storage. When there is surplus power on the grid, the office can be cooled a bit more, say $0.75^{\circ} \mathrm{C}$ lower than the set temperature and when there is deficit, the room temperature could be allowed to go a bit higher, say $0.75^{\circ} \mathrm{C}$ more than the set temperature. This fine control can be carried out using VAVs and VFD. It is found that upto 30\% energy can be saved during power-deficit situation for a short period of time, using this technique.

\section{Electrical Battery as a Storage}

The third kind of storage is the standard electrical battery at each of the offices. The offices in India typically uses batteries to provide Uninterrupted Power Supply (UPS). The battery size could be increased, and part of the battery could continue to be used for a battery back-up in case of power failure. But rest of 
the battery could be used to power partially or fully the office load when grid is in deficit state. On the other hand, this part of the battery could be charged, when grid is in surplus state. This would make the load respond to Available Power.

The three kinds of storages would make the building load respond the Available Power on the grid. Such buildings would help stabilize the grid. What is needed is that APRL is adopted by more and more multi-storied complexes. For this to happen, they need to be incentivized by the utility. For instance, the grid-tariff could be increased to ₹ 12 per unit of power during deficit state on the grid, as opposed to ₹ 8 per unit, which is charged today and which could continue to be the tariff in the Normal Grid state. On the other hand, when the grid is in surplus state, the tariff could be dropped to ₹ 4 per unit. The extent to which a building would save in such a situation is discussed in the next section.

\section{A Case Study for a Multi-storied Building}

To understand how APRL would work and the extent of savings that it would provide, a simulation was carried out for a specific multi-storied office complex. Table 1 gives the parameters assumed for the building, with the rated capacities and daily usage pattern. Figure 1 shows assumed energy consumption by different loads at different hours of the day. The logic used in the simulator is as follows:

1. Charge storage (electrical battery, chilled water storage and Cold Air storage) at maximum rate, when power is surplus.

2. Use storage to the maximum extent during deficit grid state.

3. Charge or discharge storage during Normal grid state, taking into account grid-state pattern learned from previous days, to enable minimum power usage during deficit state.

Figure 2 shows typical (i) total power demand in MW during each of $24 \mathrm{~h}$, (ii) actual grid power usage in MW during different hours when APRL is invoked, (iii) solar power generated in each hour, (iv) change in chilled water storage during each hour and (v) change in battery storage during each hour. It also shows when the grid is in surplus(S), normal(N) and deficit(D) states at different hours. Figure 3 shows the grid power costs per hour in ₹, if APRL is not used vs. when it is used. The total cost saving due to APRL amounts to ₹ 1.6 lakhs per day or about ₹50 lakhs per month, amounting to a little over $20 \%$ of the total electrical costs. Note that this is due to APRL and this saving is over and above the savings envisaged due to (i) use of DC equipment, (ii) use of VFD in AHU and VAVs and (iii) use of roof-top

Table 1 Electrical and storage parameters for a typical large multi-storied office complex, where APRL is implemented

\begin{tabular}{|c|c|c|c|}
\hline Category & Parameters & Value & Remarks \\
\hline \multirow{3}{*}{$\begin{array}{l}\text { Building Load } \\
\text { with usage vary- } \\
\text { ing at different } \\
\text { times }\end{array}$} & Peak Chiller power used & $4 \mathrm{MW}$ & Total energy used in $24 \mathrm{~h}: 43.1 \mathrm{MWh}$ \\
\hline & $\begin{array}{l}\text { Max power used by Pumps } \\
\text { and AHUs }\end{array}$ & $\begin{array}{l}1 \quad \text { MW } \\
(25 \% \text { of } \\
\text { chiller } \\
\text { power) }\end{array}$ & Total energy in $24 \mathrm{~h}$ is $10.775 \mathrm{MWh}$ \\
\hline & $\begin{array}{l}\text { Maximum power used for } \\
\text { lights and for office equip- } \\
\text { ment }\end{array}$ & $5 \mathrm{MW}$ & Total energy in $24 \mathrm{~h}$ is $52.5 \mathrm{MWh}$ \\
\hline Rooftop Solar & Plant capacity & $1 \mathrm{MW}(\mathrm{p})$ & \\
\hline \multirow[t]{3}{*}{ Storage used } & $\begin{array}{l}\text { Electrical Battery storage } \\
\text { distributed across different } \\
\text { offices effective }\end{array}$ & $10 \mathrm{MWh}$ & $\begin{array}{l}\text { I. } 50 \% \text { is assumed to be used as power back-up; } 50 \% \text { is } \\
\text { used for APLR ( } 8 \% \text { of energy used in } 24 \mathrm{~h} \text { ) } \\
\text { II. Maximum charge and discharge rate of } 0.15 \mathrm{MW} \text { is } \\
\text { assumed }\end{array}$ \\
\hline & Chilled water Storage & 20MWh & $\begin{array}{l}\text { charged / discharged at a maximum rate of } 4 \mathrm{MW} \text {. Storage } \\
\text { is almost } 50 \% \text { of chilled water energy used in } 24 \text { hours }\end{array}$ \\
\hline & $\begin{array}{l}\text { Cold Air Storage in different } \\
\text { offices }\end{array}$ & & $\begin{array}{l}\text { assumed to be able to reduce power consumption for } \\
\text { maximum of } 2 \text { consecutive hours giving } 25 \% \text { savings in } \\
\text { chilled water usage and pump and AHU power usage; also } \\
\text { needs } 2 \mathrm{~h} \text { to restore before used again. }\end{array}$ \\
\hline Grid & Three Grid States: & & Grid cost differs throughout day based on demand supply \\
\hline consumption & a. Surplus & a. ₹4 & match \\
\hline \multirow[t]{2}{*}{ Cost } & b. Normal & b. ₹8 & \\
\hline & c. Deficit & c. ₹12 & \\
\hline
\end{tabular}


Fig. 1 Energy consumption of different loads at different hours of the day

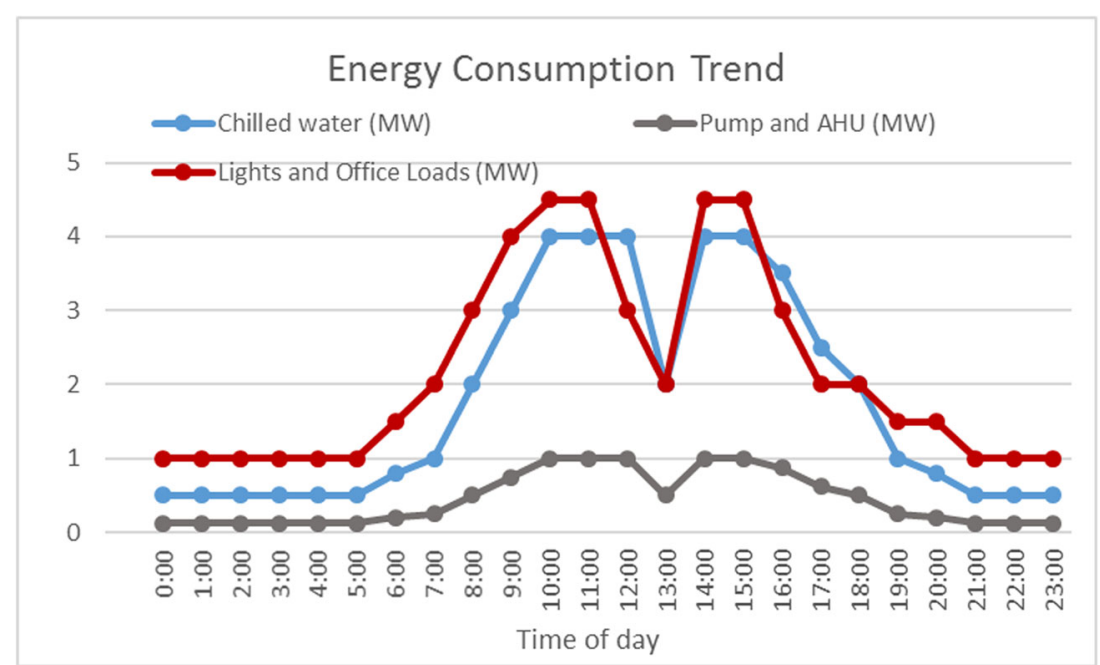

solar. Taking all these into account, the power-architecture of the buildings makes immense sense.

Kindly note that the results obtained depend upon the state of the grid at different times. In the simulation carried out, the grid state was varied only every $1 \mathrm{~h}$. If the variation is carried out every $15 \mathrm{~min}$, savings are likely to increase. Similarly, in the data used, the surplus state was assumed to be only between mid-night and 6 am and only $1 \mathrm{~h}$ during day. If the surplus state starts appearing more frequently, the savings will increase. Further, we had assumed that the electrical battery, distributed over all the offices amounted to a total of 4-h storage, of which 2-h storage was to be used strictly for back-up and only 2-h storage was available for APRL. If this size is increased, the savings could be much more. In fact, if the rate of charge / discharge of the battery was not limited to $0.15 \mathrm{C}$, one could have got larger gains. Similarly, chiller storage was assumed to be 20 MWh with charge / discharge rate limited to $4 \mathrm{MW}$. If the total storage or the rate was increased, the gains would be more. Finally, the grid was assumed to be in three states and tariff of ₹4, ₹8 and ₹12 per unit was used for the surplus, normal and deficit state respectively. If one uses two more states, that is high surplus and high deficit and grid tariff is decreased and increased accordingly, APRL may give larger gains. Please also note that we have assumed no power-cuts for the building. Buildings that encounter power-cuts would benefit more due to storage and APRL.

\section{Building Designed to be Ready for APRL}

The proposed concept has been implemented in Phase II of Research Park, IIT Madras which is a $800 \mathrm{~K}$ sq $\mathrm{ft}$ office building area and a $265 \mathrm{~K}$ sq $\mathrm{ft}$ multi-storied parking lot. Chilled thermal insulated system can store $300 \mathrm{~K}$ litres of chilled water at $6-8{ }^{\circ} \mathrm{C}$. Chillers are installed with capacity of 900 TR for Phase -I, and with capacity 1700 TR for Phase -II. AHUs consume $561 \mathrm{~kW}$ and pumps consume $278 \mathrm{~kW}$ with the given diversity of $75 \%$. Solar plant is sized at $1.1 \mathrm{MW}$ out of which $286 \mathrm{kVA}$ has already been installed. Total light and office load are expected to generate a maximum demand of $2250 \mathrm{kVA}$. Building management system has been designed to implement APRL.
Fig. 2 Power generation, storage and consumption trends in a day

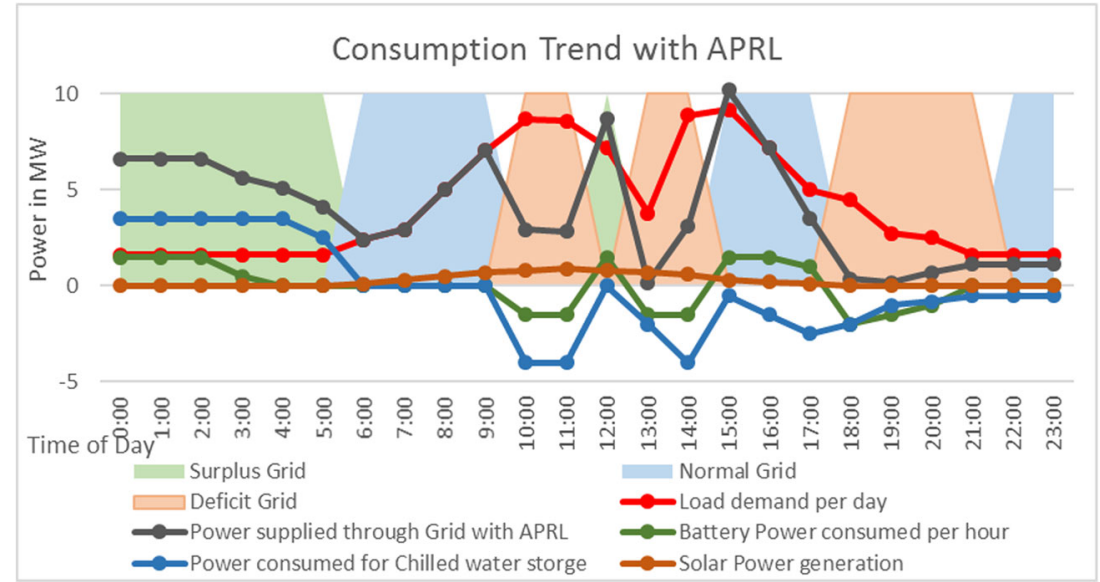


Fig. 3 Comparison of expenses on grid power consumed with APRL and without APRL for different states of grid

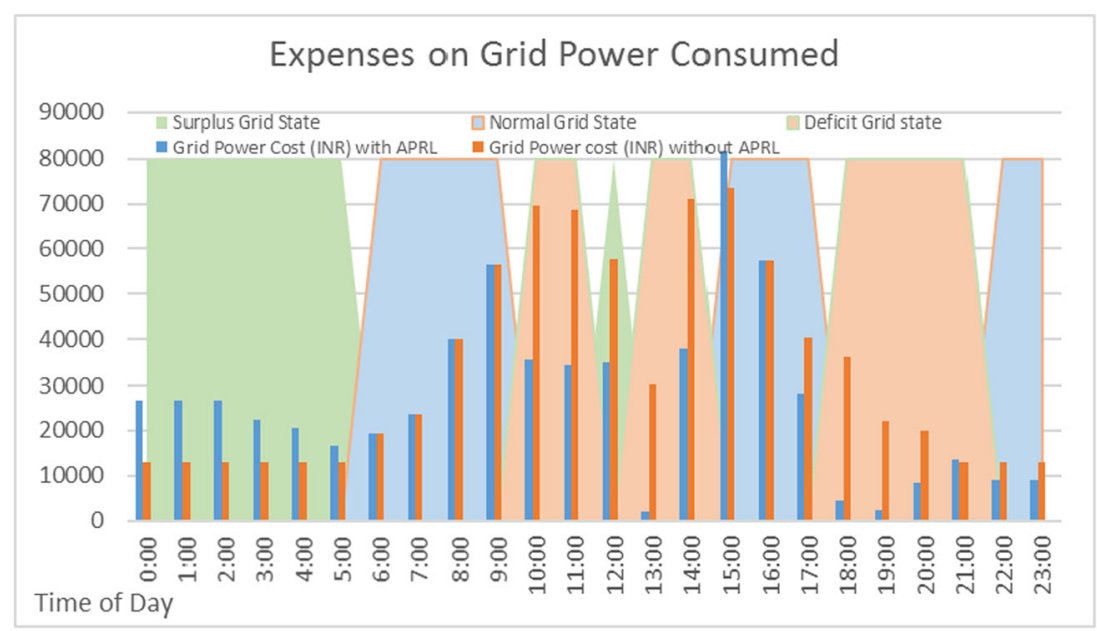

\section{Summary and Conclusion}

Technologies for Renewable energy has been advancing rapidly while the costs, especially of solar PV systems, is falling. As power-costs from renewables become comparable to that of the thermal power-costs, stage is set for renewables toplay dominant role in a nation's power generation. The bottleneck comes from the fact that the renewable power generation is intermittent and varies from time to time. It is not controllable and the quantity of power generated would depend upon the nature. Since the power used needs to match the generated power at each instant, one option would be to vary the conventional power generation so that the load and supply are matched. But this has two problems. Firstly, the conventional power-plant is not optimally used increasing the cost of generation. Secondly, while this approach could be used when renewables is a small percentage of total power generation, it becomes difficult, as renewable power starts dominating the grid.

An alternative will be to use storage on the grid. But this is expensive and would make power costs unviable. This paper suggests another alternative in the form of distributed APRL. Here the consumer is incentivised to deploy different forms of storage and consume less when the grid is in deficit state and more when the grid is in the surplus state. These could be chilled water storage or cool air storage or electrical battery storage in each office. The storage is filled during power surplus state and used during power deficit stage. The incentive is provided by utilities with lower tariff during surplus and higher tariff during deficit state. The consumer would then contribute towards stabilizing the grid in the process of saving costs.

The simulation carried out in "A Case Study for a Multistoried Building" shows the extent of saving for a consumer to be as high as $20 \%$ of power bill. Further, in the simulation the grid-tariff was varied only once in an hour. If the tariff is varied every 15 min depending upon the state of the grid, the savings is expected to be higher. This is in addition to the savings obtained from energy-efficient appliances and techniques discussed here. Even though detailed study on investments required and the returns is yet to be carried out, the savings is so significant that the investment is expected to be returned in a very short time.

But above all, the approach will move us in direction towards ability to use renewables, even if they start dominating the total grid power. In a sense, this will help us get to a renewable future. The next task will be to extend the approach beyond commercial buildings. One can learn from this sector and design APRL for industry, domestic and transport sector. Only this will prepare us to go Renewables whole hog.

\section{References}

1. Annual Report 2016-17, Ministry of Power, Government of India. Accessed on 6th June, 2017. http://powermin.nic.in/sites/default/ files/uploads/MOP_Annual_Report_2016-17.pdf

2. Programme Scheme wise Physical Progress in 2016-17. http:// www.mnre.gov.in/mission-and-vision-2/achievements/

3. Naam R (2015) How cheap can energy storage get? Pretty darn cheap. http://rameznaam.com/2015/10/14/how-cheap-can-energy-storage-get/

4. Vazquez S, Lukic SM, Galvan E, Franquelo LG, Carrasco JM (2010) Energy storage systems for transport and grid applications. IEEE Trans Ind Electron 57(12):3881-3895

5. The case for $48 \mathrm{~V}$ lighting system. A report on XICATO. www. xicato.com/sites/default/files/documents/TheCasefor48VDC_0. pdf

6. Energy efficiency in lighting; AC vs DC lighting. Report by Centre of Excellence for Decentralised power systems, IIT Madras

7. Shenai K, Jhunjhunwala A, Kaur P (2016) Electrifying India: Using solar dc microgrids. IEEE Power Electron Mag 3(4):42-48

8. Sirsi R, Prasad S, Sonawane A, Lokhande A (2016) Efficiency comparison of AC distribution system and DC distribution system in microgrid. In: 2016 international conference on energy efficient technologies for sustainability (ICEETS), pp 325-329 